\title{
Complications Caused by Hearing Aid Mold Impression Material - Clinical Case and Literature Review
}

\author{
Sergey Korsakov*, Alexander Gunenkov and Ekaterina Pchelenok \\ Department of Otorhinolaryngology, Russian Medical Academy of Continuing Postgraduate Education, Russia \\ *Corresponding author: Sergey Korsakov, Department of Otorhinolaryngology, Russian Medical Academy of Continuing \\ Postgraduate Education, Ministry of Health of Russia, Moscow, Russia
}

\begin{abstract}
A clinical case of the procedure of ear mold impression complication is discussed. The review deals with complications caused by hearing aid mold impression and is compared with a specific example.
\end{abstract}

Keywords: Silicone; Impression Material; Middle Ear; Foreign Body

\section{Introduction}

The procedure for producing an ear mold impression is common for final fitting of hearing aid or ear plugs. Routinely a cotton ball with thread (called otoblock) is inserted in the external ear canal to prevent the colored silicone material that is introduced later to flow too close to the tympanic membrane (TM). If the otoblock is installed improperly complications may occur

\section{Case Presentation}

A 60-year-old woman applied to our clinic with the complaints of otorhea from her left ear, otalgia and binaural hearing loss which was more severe on the left side. She had suffered chronic otitis media on both ears from childhood. According to medical documents tympanoplasty on the left ear was performed with fascia in 2008, and on the right in 2013. In 2017 the polyp was removed from the left tympanic cavity and post-procedure otoscopy revealed central perforation with no discharge. The patient was fitted with a hearing aid for the right ear. Soon she referred to the Hearing Aid Center where an impression mold procedure on the left ear took place. The introduction of the silicone material induced otalgia and vertigo. According to medical papers the hearing aid specialist did not report any complications of the manipulation. Nevertheless, antibacterial drops were prescribed. During a period of several months the patient consulted with a private ENT doctor, however no new impairment was detected. 11 months later she was referred to our clinic. Otoscopy of the right ear revealed retraction of the MT. In the left ear serous discharge from the central perforation of the MT was revealed and granulation tissue in posterior inferior part of the TM. CT imaging showed mastoid cavity sclerosis and foreign body in the hypotympanum (Fig 1). Pure tone audiometry revealed mixed severe hearing loss. The patient was scheduled for revision of tympanic cavity and tympanoplasty. While in surgery we observed a foreign body in the hypotympanum that looked similar to the impression silicone, which was carefully removed. Inferior and posterior walls of the external ear canal were slightly remodeled before the removal of the material (Figure 2). In the tympanic cavity mucous tissue with oedema and granulation tissue were revealed; the ossicular chain was intact. The tympanoplasty was performed with a chondro-perichondrium graft. We left the mastoid cavity intact since the inflammation was localized in the tympanic cavity only. Otoscopy one month later revealed healing of TM perforation and external ear canal (Figure 3).

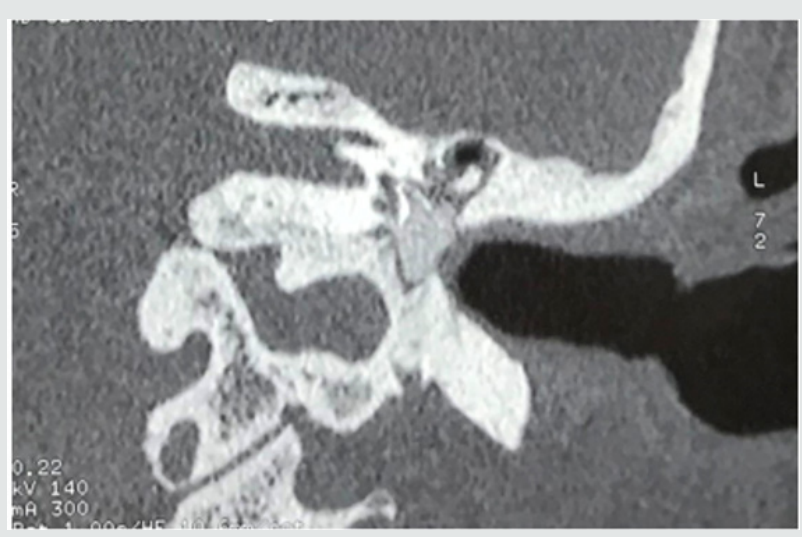

Figure 1: Coronal CT imaging. In hypotympanun the foreign body is visualized (A). 


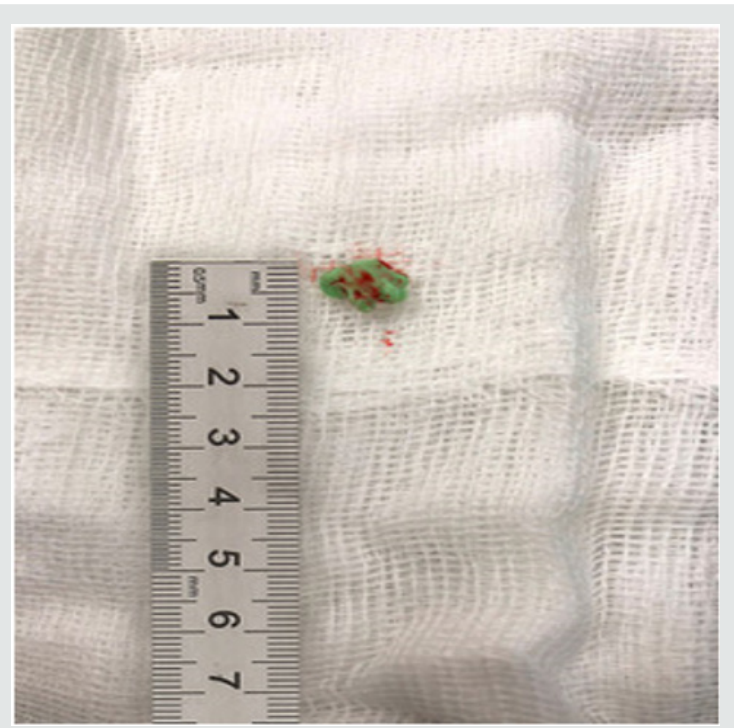

Figure 2: The removed impression material.

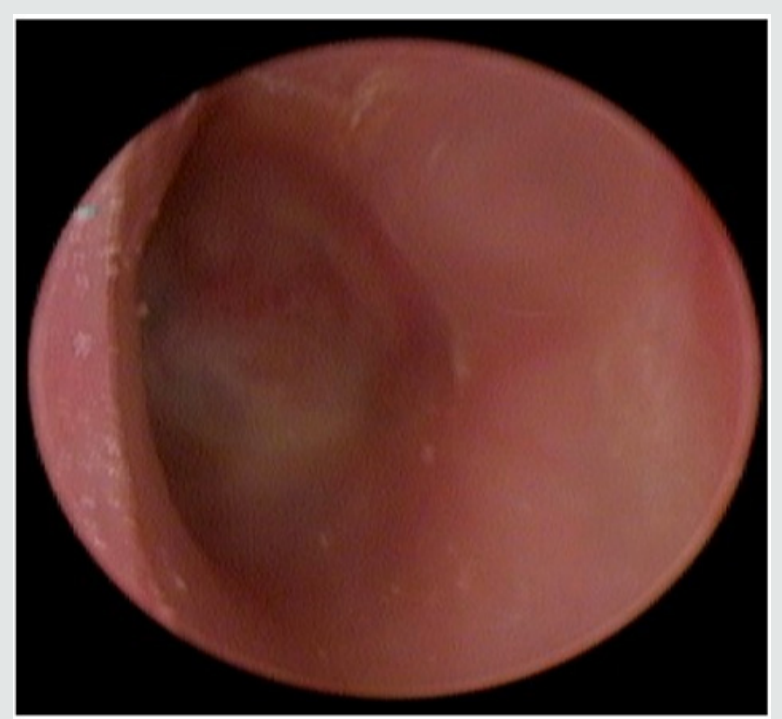

Figure 3: Otomicroscopy 1 month since the operation. Neotympanic membrane (A) without perforation and no inflammation.

\section{Discussion}

The procedure of making impression of ear mold is rather routine and safe in the vast majority of cases. However, complications sometimes occur as it had happened to our patient and is occasionally discussed in literature as well, from the failure to remove the silicone, to its protrusion to the tympanic cavity and ossicular erosion later on [1]. The symptoms are otalgia and fullness while the procedure, and otorhea, hearing loss, otalgia and vertigo afterwards. It's considered that erosion of the wall of the semicircular canal is the cause of the vertigo [2]. Seems that the gravity of the complications increases with the duration of the foreign body stay in tympanic cavity [3]. Impression material protrusion more often happens in patients with predisposing factors, such as TM perforation and grommets. Though 5 cases are described for the traumatic perforation due to the manipulation [1].Spontaneous healing of the TM can happen, leaving patients with otalgia and conductive hearing loss [4]. Another high-risk factor is wall down surgery which leads to difficulties for the correct and sufficient fitting of an otoblock while manipulating [5]. CT is an important diagnostic instrument for the visualization of the impression material and is the preoperative map that leads to minimize surgical complications in such cases. Verdam F et al. [6] propose the algorithm to rule out the complications.

In patients with otalgia only and in obvious cases without TM perforation observed in otoscopy before the fitting procedure, the experienced specialist can remove the silicone. If the manipulation increases pain or MT was not observed beforehand, the referral to experienced ENT surgeon is strongly recommended and CT could be useful. The symptoms mentioned above or other symptoms including otalgia require the $\mathrm{CT}$. If the imaging shows the impression material localization in the external ear only it could be removed under local anesthesia. In cases with middle ear involvement surgery with general anesthesia is required [6]. According to S Leong et al. in $36 \%$ of cases hearing loss deteriorated. The erosion of the ossicles, soft tissue proliferation, perilymphatic fistula could all be possible reasons for this. In addition, results of surgery decrease due to in sufficient visualization, incorrect surgical instrument and renunciation of CT [1]. Most of the papers deal with patients' referral for the impression material removal directly after treatment, however in some cases it is left in the middle ear for months and even years. Our patient had surgery approximately one year ago. Colleagues observed cases of discovery and removal 4 years and 8 months [2], 9 years [7] and even 15 years [8] after hearing aid fitting procedure. In the latter case the old man didn't use hearing aid and he and his relatives have forgotten the manipulation. Undoubtedly the best option to avoid these complications is the development of the equipment scanning of the external ear without the impression material. Unfortunately, this technology is not developed yet to be clinically applied.

\section{References}

1. Leong SC, Banhegyi G, Panarese A (2012) Serious complications during aural impression - taking for hearing aids: a case report and review of the literature. The Annals of otology, rhinology, and laryngology 121: 516-520.

2. Suzuki N, Okamura K, Yano T (2015) Silicone impression material foreign body in the middle ear: Two case reports and literature review. Auris Nasus Larynx 42(5): 419-423.

3. Lee DH, Cho HH (2012) Otologic complications caused by hearing aid mold impression material. Auris Nasus Larynx 39(4): 411-414.

4. Kohan D, Sorin A, Marra S, Gottlieb M, Hoffman R (2004) Surgical management of complications after hearing aid fitting. Laryngoscope 114: $317-322$

5. Jacob A, Morris TJ, Welling DB (2006) Leaving a lasting impression: ear mold impressions as middle ear foreign bodies. The Annals of otology, rhinology, and laryngology115(12): 912-916.

6. Verdam F, Tange R, Thomeer H (2016) Impression material in the external and middle ear: an overview of the literature and a stepwise approach for removal. The Journal of International Advanced Otology 12(3): 345-352. 
7. Awan MS, Iqbal M, Sardar ZI (2007) Iatrogenic insertion of impression mould into middle ear and mastoid and its retrieval after 9 years: a case report. Journal of medical case reports 2:1-3.
8. Yoshioka S, Inuzuka E, Kato H, Naito K, Suzuki Y, et al. (2017) Surgical removal of hearing aid ear mold impression material from the middle ear: a report of two cases. Fujita Medical Journal 3(3): 72-75. (c) (P)

This work is licensed under Creative Commons Attribution 4.0 License

To Submit Your Article Click Here:

Submit Article

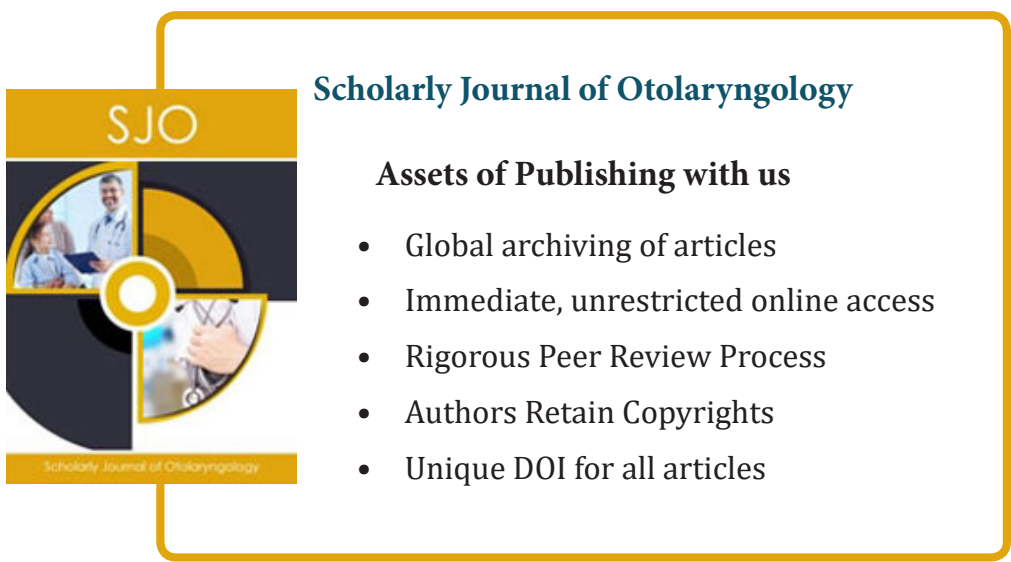

